\title{
Tomography-like retrieval of auroral volume emission ratios for the 31 January 2008 Hotel Payload 2 event
}

\section{C.-F. Enell ${ }^{1}$, B. Gustavsson ${ }^{2}$, B. U. E. Brändström ${ }^{3}$, T. I. Sergienko ${ }^{3}$,} P. T. Verronen ${ }^{4}$, P. Rydesäter ${ }^{5}$, and I. SandahI ${ }^{3, \dagger}$

${ }^{1}$ Sodankylä Geophysical Observatory, University of Oulu, Sodankylä, Finland

${ }^{2}$ School of Physics and Astronomy, University of Southampton, Southampton, UK

${ }^{3}$ Swedish Institute of Space Physics, Kiruna, Sweden

${ }^{4}$ Finnish Meteorological Institute, Helsinki, Finland

${ }^{5}$ SenseAir AB, Delsbo, Sweden

${ }^{\dagger}$ Deceased, 2011. This paper is dedicated to her memory.

Received: 1 December 2011 - Accepted: 18 December 2011 - Published: 5 January 2012

Correspondence to: C.-F. Enell (carl-fredrik.enell@sgo.fi)

Published by Copernicus Publications on behalf of the European Geosciences Union.

HotPay 2 event auroral emission ratio retrieval

C.-F. Enell et al.

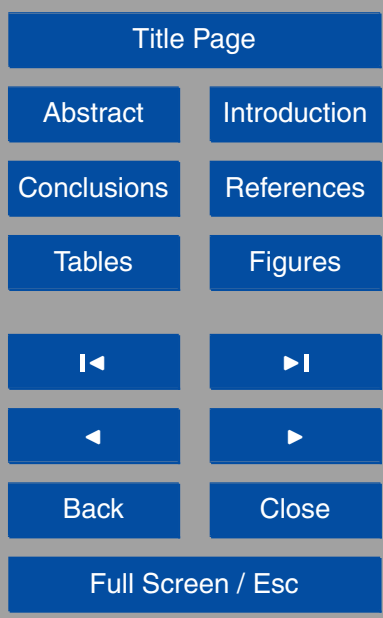

Printer-friendly Version

Interactive Discussion

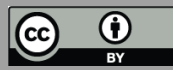




\section{Abstract}

Quantitative tomography-like volume estimates of the $\mathrm{N}_{2}^{+}(1 \mathrm{~N})$ emission at $427.8 \mathrm{~nm}$, the $O\left({ }^{1} \mathrm{~S}\right)$ emission at $557.7 \mathrm{~nm}$ and the $O\left({ }^{1} \mathrm{D}\right)$ emission at $630.0 \mathrm{~nm}$ can be retrieved from data from the Auroral Large Imaging System (ALIS) remote-controlled spectral 5 imagers operated at field stations in northern Sweden and Norway. This paper presents a case study of a quiet auroral arc passing over the common volume of the imagers in the evening of 31 January 2008, before the launch of the Hotel Payload 2 (HotPay 2) rocket from Andøya Rocket Range.

The reconstructed spectroscopic ratios at the lower altitudes close to the mesopause 10 region can be used as indicators of the $\mathrm{NO}$ and $\mathrm{O}$ profiles, as the atomic oxygen $\mathrm{O}\left({ }^{1} \mathrm{~S}\right)$ and $O\left({ }^{1} D\right)$ states are excited partly through chemical reactions. The profiles of the ratios of the volume emission rates $\epsilon_{557.7}$ and $\epsilon_{427.8}$ observed by ALIS over northern Norway show nothing unambiguously unusual within the accuracy of the calibration and retrieval, whereas HotPay 2 indicated subsidence of lower thermospheric air, with lite instruments, which indicate subsidence in vortex filaments only in the NW as seen from the Scandinavian mainland.

\section{Introduction}

Current development of radar and optical instruments for atmospheric studies aims 20 at 3-D imaging. In this study we apply multistatic, monochromatic measurements of optical emissions in order to iteratively construct tomography-like estimates of auroral volume emission rates.

The retrieval has been performed for the $427.8,557.7$ and $630.0 \mathrm{~nm}$ auroral emissions in a simple test case: the stable auroral arc that was observed shortly before the launch of the Hotel Payload 2 (HotPay 2) rocket (Enell et al., 2011) on 31 January 2008. The intention of the rocket measurements was to study any local production

\section{GID}

2, 1-21, 2012

\section{HotPay 2 event auroral emission ratio retrieval}

C.-F. Enell et al.

\section{Title Page}

Abstract

Introduction

Conclusions

Tables

References

Figures

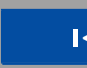

14

$\Delta$

4

Back

$\checkmark$

Close

Full Screen / Esc

Printer-friendly Version

Interactive Discussion

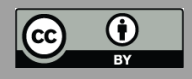


of nitric oxide (NO) caused by dissociation of molecular nitrogen in the aurora. However, the [NO] and electron density profiles measured by HotPay 2 and coordinated ground-based incoherent scatter radar measurements turned out to be indicative of subsidence of thermospheric air due to polar vortex dynamics. If this were the case 5 also in the common volume of the imagers, the volume emission ratios could possibly deviate from those theoretically or empirically expected, but this turns out not to be the case within the accuracy of the observation. SciSat ACE measurements of NO were available, confirming the very structured nature of the lower-thermospheric profiles. In this study also EOS Aura MLS maps confirm this structure of subsidence in polar vortex 0 filaments (Fig. 7).

\section{The Auroral Large Imaging System (ALIS)}

ALIS (Brändström, 2003) is a system of CCD imagers, each equipped with a medium (70-100 diagonal) field-of-view front lens and telecentric optics with a six-position filter wheel for imaging spectral radiometry. All ALIS imagers have filters with pass-bands 15 around the following auroral emissions:

- $\mathrm{N}_{2}^{+}$first negative emission band at $427.8 \mathrm{~nm}$

- $O\left({ }^{1} S\right) \rightarrow O\left({ }^{1} D\right)$ at $557.7 \mathrm{~nm}$

$-\mathrm{O}\left({ }^{1} \mathrm{D}\right) \rightarrow \mathrm{O}\left({ }^{3} \mathrm{P}\right)$ at $630.0 \mathrm{~nm}$

The $\mathrm{N}_{2}^{+}$emission is prompt and is a direct measurement of auroral energy deposition, whereas the two oxygen emissions are dipole-forbidden and long-lived. The $O\left({ }^{1} S\right)$ and $\mathrm{O}\left({ }^{1} \mathrm{D}\right)$ states are excited partly through chemistry involving i.a. $\mathrm{O}$ and NO.

The imagers are deployed at fully autonomous, remote-controlled stations, the locations of which give baselines suitable for auroral triangulation and tomography. During the winter of 2007-2008, six imagers were located at the sites shown on the map in

\section{GID}

2, 1-21, 2012

\section{HotPay 2 event auroral emission ratio retrieval}

C.-F. Enell et al.
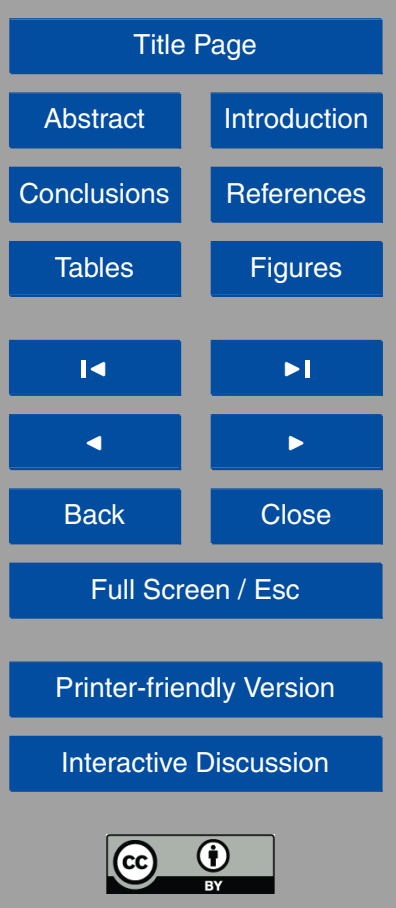
Fig. 1. Details of the imagers and the locations are listed in Table 1. Data from up to four of these sites were used in this study. The common volume was above northern Norway as shown by the overlap of the fields of view in Fig. 2.

\section{Tomography-like estimates of volume emissions}

5 Tomographic reconstruction of volume emissions, in the strict sense of the word tomography (e.g. Radon, 1917), requires knowledge of the radiance measured along an infinite number of lines of sight intersecting the emitting volume. This is not possible in practice so we take the concept of tomographic reconstruction in its usual meaning: tomography-like reconstruction of the volume emission through iterative projection to 10 and backprojection from two or more imaging stations observing a common volume. The method has been thoroughly described by Gustavsson $(2000,2010)$ but will be outlined in some detail in the following:

1. Construct a start guess of the volume emission (e.g. from an imager observing close to magnetic zenith under the arc)
2. Project the start guess to all imagers using geometric camera models based on star mapping (see Gustavsson, 2000, 2010) and the fast projection method based on volume-filling base functions, "blocks of blobs", described in Rydesäter and Gustavsson (2001)

3. Form the ratios between the observed images and volume emission estimate projections

4. Backproject the ratios into the volume and update the volume emission rates; several algorithms with different advantages and drawbacks exist (Gustavsson, 2000; Rydesäter, 2001)

5. Repeat the projections, generally including a spatial filter of decreasing kernel size

\section{GID}

2, 1-21, 2012

\section{HotPay 2 event auroral emission ratio retrieval \\ C.-F. Enell et al.}
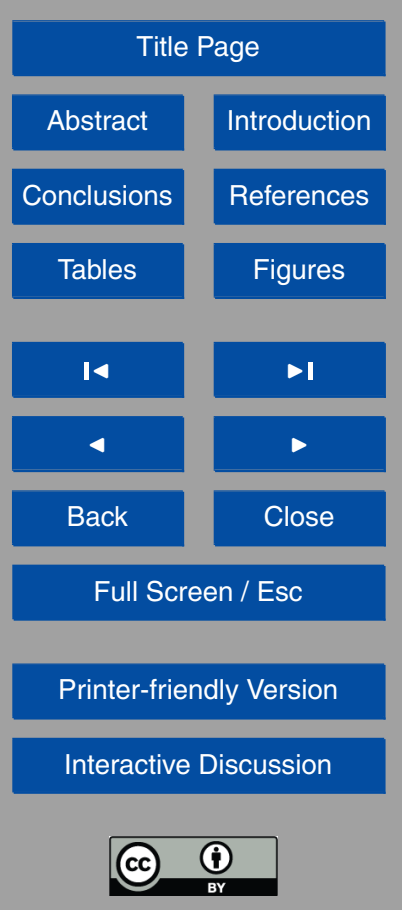
In the final online version of this paper, a link to an example of the actual Matlab code used in this work will be made available under the GNU General Public License (Free Software Foundation Inc., 2007).

\subsection{Image preprocessing}

5 The images are preprocessed as needed before further processing and application of calibration factors. Preprocessing steps always include

1. Subtraction of CCD bias

2. Correction of known bad pixels

3. Median filtering for removal of spikes (which may be caused by unknown hot pixels, cosmic rays, etc.)

As necessary also removal of structures (for example water or snow on the domes) and interference patterns (sometimes caused by electromagnetic RF noise at the remote ALIS stations) may have to be applied.

\subsection{Intensity calibration}

15 Intensity calibration is the conversion from arbitrary digital numbers of the image file to physical units of spectral radiance or column emission in a certain auroral emission line. In auroral research the column emission is usually expressed in Rayleighs (R, where

$1 \mathrm{R}=\frac{10^{10}}{4 \pi}$ photons $\mathrm{m}^{-2} \mathrm{~s}^{-1}$

20 In this paper we use calibrations from laboratory observations of standard low-light calibration sources, which are are made from radioactive ${ }^{14} \mathrm{C}$ covered with fluorescent phosphors of known spectral characteristics. The calibration factors used are shown in Table 2, expressed in Rs (Rayleighs per count per second).

\section{GID}

2, 1-21, 2012

\section{HotPay 2 event auroral emission ratio retrieval}

C.-F. Enell et al.

\section{Title Page}

Abstract Introduction

Conclusions References

Tables References

Figures
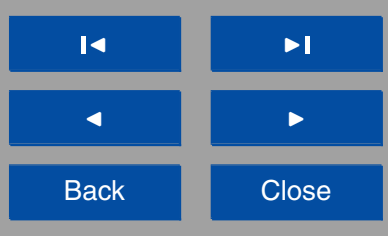

Back

Close

Full Screen / Esc

Printer-friendly Version

Interactive Discussion

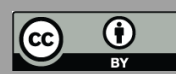


Additionally the flat-field correction, i.e. the difference in solid angle subtended by a pixel as function of pixel coordinates $(u, v)$, should ideally also be determined experimentally using a Lambertian source, such as a large integrating sphere (Urashima et al., 1999). Since we do not have easy access to such a facility, we instead make use 5 of the fact that the flat field is theoretically the Jacobian of the geometrical projection function, which we estimate from the geometrical star calibration (Gustavsson, 2010).

\subsection{Atmospheric absorption}

The absorption of the atmosphere at the wavelengths used must also be taken into account in the image projections. Assuming a horizontally homogeneous plane-parallel

$A(\lambda, \chi)=\exp \left(-\frac{\tau(\lambda)}{\cos (\chi)}\right)$

where the line-of-sight zenith angle $\chi$ is calculated for each pixel using the projection model as described below. $A$ is then introduced as an additional pixel-to-pixel sensitivity variation. The optical depth exponents $\tau(\lambda)$ assumed for the three wavelengths are 15 given in Table 2.

\section{The Hotel Payload 2 event 31 January 2008}

In the present case study we use data from the Hotel Payload 2 rocket launch day, 31 January 2008 (Enell et al., 2011). Launch criteria included clear sky and quiet to moderate auroral activity before the launch. A quiet arc passed Northern Scandisubsequently launched at 19:14 UT. Such a quiet arc provides an ideal test case for tomography-like volume reconstructions. Auroral breakup and activation occurred only later in the evening, around 21:00 UT.

\section{GID}

2, 1-21, 2012

\section{HotPay 2 event auroral emission ratio retrieval}

C.-F. Enell et al.



Printer-friendly Version

Interactive Discussion

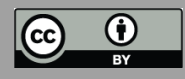


The nitric oxide and oxygen profiles measured by the rocket were clearly affected by atmospheric dynamics, showing subsidence in patches of the Arctic polar vortex, a conclusion supported also by satellite observations. Apart from providing an easy test case for the volume emission inversion, this case therefore also seemed interesting in 5 that the atypical oxygen and NO profiles may show effects in the spectroscopic volume emission ratio of the $\mathrm{O}\left({ }^{1} \mathrm{~S}\right)$ to $\mathrm{N}_{2}^{+}$first negative emissions. However, as will be seen this does not seem to be the case for the HotPay 2 day. We plan further correlated groundbased imaging, radar and satellite observations in order to confirm the method.

\section{Results: volume estimates of spectroscopic ratios}

10 The ALIS imagers were operating throughout the evening of 31 January 2008 running a sequence of exposures with filters for 3 or 4 emissions (428.8, 557.5, 630.0 and $844.6 \mathrm{~nm}$ at each station. Data from the Skibotn, Abisko and Kiruna were used in the retrieval. A block of blobs was located in the N-S, E-W and magnetic zenith directions in the common volume of the imagers and start guesses were produced by projecting 15 Skibotn data along Chapman profiles with a given altitude of maximum emission (Table 3). The retrieval is sensitive to this maximum altitude so reasonable values were obtained from triangulation on features in pairs of images.

In the following, example results of the retrieval of volume emission rates $\epsilon_{427.8}$, $\epsilon_{557.7}$ and $\epsilon_{630.0}$ are presented. We concentrate on the results from 14 sets of images 20 exposed at times 18:00-18:09 UT. Figure 3 shows 2-D slices interpolated from the resulting volume emission block of blobs in the common volume over northern Scandinavia at 18:04 UT, as an example of the results. In Fig. 4 3-D volume renderings are shown. The online version of this paper will include animations of the results for the whole time interval.

25 The data presented in the figures are all from the central part of the overlapping volume, in order to avoid the boundaries of the fields of view, where image pixels inevitably have to be projected along the bounding planes or lines causing artifacts (see

\section{GID}

2, 1-21, 2012

\section{HotPay 2 event auroral emission ratio retrieval}

C.-F. Enell et al.

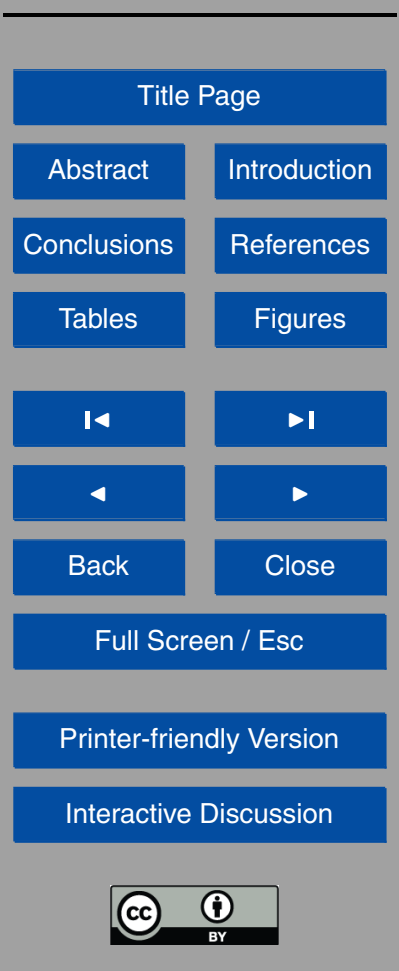


the examples in Gustavsson, 2010). Auroral arcs show temporal and spatial variations on many scales but the arc studied in this case was varying slowly compared to the exposure time and imaging interval. Therefore the inversion of volume emission rates worked out reasonably well in a few iterations.

\section{Effects of chemical composition}

Figure 5 shows profiles volume emission rate ratios, calculated inside boxes at the maximum of the arc. The horizontal limits of these boxes were selected manually and emission rate profiles were then interpolated from the blocks of blobs inside the boxes. At each altitude the median of the interpolated emission was selected.

10 As the blue line emission is prompt it is a direct measure of auroral energy deposition, whereas the red line emission, with its long radiative lifetime of over $100 \mathrm{~s}$ (VallanceJones, 1974), is heavily quenched at low altitudes. This is evident also in the present results. The more short-lived green line emission, on the other hand, follows the blue line emission with an almost constant ratio at altitudes below some $200 \mathrm{~km}$. The exact 15 ratio, however, is expected to depend especially on the concentration of atomic oxygen. In Fig. 6 we show the theoretical volume emission ratios as calculated with an emission model based on Ivanov et al. (1993) for the MSIS (Hedin, 1991) background atmosphere for 31 January 2008, 18:00 UT, at Tromsø $\left(69.48^{\circ} \mathrm{N}, 19.22^{\circ} \mathrm{E}\right)$. The model assumes a Maxwellian energy distribution of the electron precipitation. Although the absolute emission rates and peak altitude differ for different characteristic energies, their ratios are approximately constant and Fig. 6 therefore shows the ratios for only one characteristic energy, $1 \mathrm{keV}$. Considering the observed altitude of maximum arc intensity and the this energy is somewhat overestimated. It can be seen that the overall features are the same as of the observations. The shape of the red-to-blue ratio differs whereas the green-to-blue ratio at the lower altitude range of the simulation agrees surprisingly well with the measurements within the accuracy of the retrieval. At the lowermost altitudes the ratios differ, and these deviations may indicate atypical NO or

\section{HotPay 2 event auroral emission ratio retrieval}

C.-F. Enell et al.
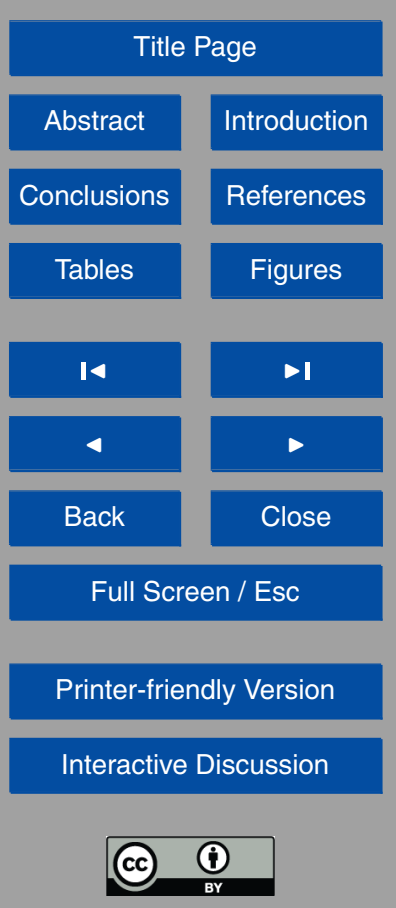
O profiles. Figure 7 shows mesospheric temperature and carbon monoxide measurements from EOS/Aura MLS data. Although from lower down in the mesosphere these data suggest that the subsidence of thermospheric air observed as atypical oxygen and nitric oxide profiles by the Hotel Payload 2 rocket (Enell et al., 2011) were localised 5 west of the Scandinavian mainland in filaments of the polar vortex. Thus it cannot be unambiguously stated whether there is an effect of differences in chemical composition. The actual atmospheric attenuation (especially Rayleigh scattering in the blue) may cause a systematic offset at low elevations. For future measurements we will use an absolute intensity calibration from star spectra, which automatically removes the ef10 fect of the atmosphere, the absorption of the dome and the transmission of the optical system.

\section{Conclusions}

Volume emission rates of the Hotel Payload 2 event quiet auroral arc were obtained in a few iterations of block of blobs projection and backprojection.

15 The method presented is suitable for cases with quiet auroral arcs, structures stationary within the time resolution of the observations. For active aurora the method is less suitable but fortunately quiet arcs are not uncommon in the evening sector over Northern Scandinavia.

The spectroscopic ratio profiles calculated from the retrieved volume emission in this 20 case can be taken as typical for our method and calibration. As only the relative ratios and not absolute volume emissions are considered.

Therefore the present study can be considered a zero result. Further investigation and better absolute calibration is necessary. If the method turns out to work it will provide a valuable additional means of remote sensing chemistry of the lower thermeasurements for validation of the method.

\section{GID}

2, 1-21, 2012

\section{HotPay 2 event auroral emission ratio retrieval}

C.-F. Enell et al.

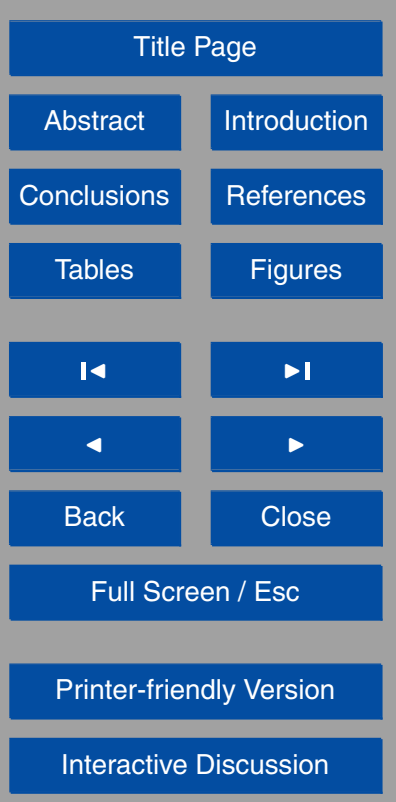




\section{Supplementary material related to this article is available online at: http://www.geosci-instrum-method-data-syst-discuss.net/2/1/2012/ gid-2-1-2012-supplement.zip.}

Acknowledgements. During this study CFE has partly been funded by the Academy of Finland 5 through project 11232755 - Thermosphere and Mesosphere affecting the Stratosphere.

The Auroral Large Imaging System is supported by the Swedish Research Council (VR), and the Hotel Payload rocket launch from Andøya Rocket Range was funded by the European Union FP6 project RITA-CT-2003-506208 (ALOMAR eARI - enhanced Access to Research Infrastructure).

10 The authors also gratefully acknowledge travel support and workshops funded by the Nordic Council of Ministers through the Network for Groundbased Optical Auroral Research in the Arctic Region (NordAuropt).

\section{References}

Brändström, U.: The Auroral Large Imaging System - Design, operation and scientific results, Ph.D. thesis, Swedish Institute of Space Physics, Kiruna, Sweden, IRF Scientific Report 279, ISBN 91-7305-405-4, 2003. 3

Enell, C.-F., Hedin, J., Stegman, J., Witt, G., Friedrich, M., Singer, W., Baumgarten, G., Kaifler, B., Hoppe, U.-P., Gustavsson, B., Brändström, U., Khaplanov, M., Kero, A., Ulich, T., and Turunen, E.: The Hotel Payload 2 campaign: Overview of NO, $\mathrm{O}$ and electron density measurements in the upper mesosphere and lower thermosphere, J. Atmos. Sol.-Terr. Phy., 73, 2228-2236, doi:10.1016/j.jastp.2011.01.001, 2011. 2, 6, 9, 16, 21

Free Software Foundation Inc.: GNU GENERAL PUBLIC LICENSE Version 3, http://www.gnu. org/licenses/gpl.html, 2007. 5

Gustavsson, B.: Three Dimensional Imaging of Aurora and Airglow, Ph.D. thesis, Swedish Inst. of Space Physics, Kiruna, ISBN 91-7191-878-7, 2000. 4

Gustavsson, B.: Multi view-point image analysis, available on request from the authors, 2010. $4,6,8$

\section{GID}

2, 1-21, 2012

\section{HotPay 2 event auroral emission ratio retrieval}

C.-F. Enell et al.

Hedin, A. E.: Extension of the MSIS Thermospheric Model into the Middle and Lower Atmosphere, J. Geophys. Res., 96, 1159-1172, 1991. 8

Ivanov, V. E., Kirillov, A. S., Sergienko, T. I., and Steen, Å.: Modelling of the altitude distribution of green line $(\lambda 5577 \AA)$ luminosity of aurora, in: Airglow and Aurora, Proc. SPIE, Vol. 2050, edited by: Leontiev, S., SPIE Optical Engineering Press, 105-113, 1993. 8

Radon, J.: Über die Bestimmung von Funktionen durch ihre Integralwerte längs gewisser Mannigfaltigkeiten, Ber. Sächsische Akad. Wiss., Math. Phys. KI, 69, 262-277, 1917. 4

Rydesäter, P.: Processing of multi-station auroral image data, Lic. thesis, Applied Physics and Electronics, Umeå University, Umeå, Sweden, ISBN 91-7305-149-7, 2001. 4

Rydesäter, P. and Gustavsson, B.: Investigation of smooth basis functions and an approximated projection algorithm for faster tomography, Int. J. Imag. Syst. Tech., 11, 347-354, 2001. 4

Urashima, A., Aso, T., Ejiri, M., Steen, A., Brändström, U., and Gustavsson, B.: Camera calibration by integrating sphere for the auroral tomography observation, Adv. Polar Upper Atmos. Res., 13, 79-88, 1999. 6

Vallance-Jones, A.: Aurora, in: Geophysics and astrophysics monographs, vol. 9, D. Reidel Publishing Company, ISBN 90-277-0272-1, 1974. 8

\section{GID}

2, 1-21, 2012

\section{HotPay 2 event auroral emission ratio retrieval}

C.-F. Enell et al.

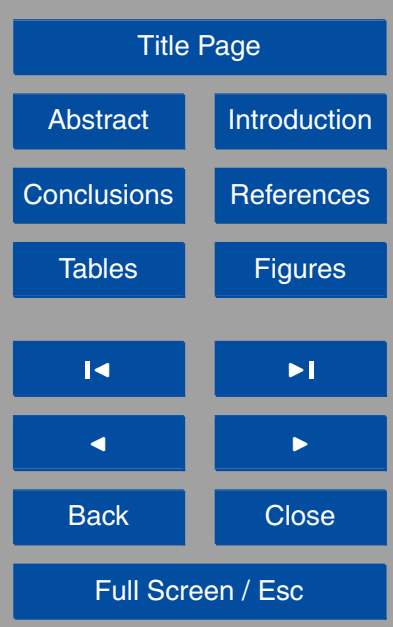

Printer-friendly Version

Interactive Discussion

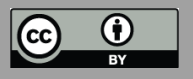


Table 1. Location of the ALIS imagers during the winter 2007-2008. In this study data from at most 4 of the imagers were used. Imager 1 (station 0 ) had moisture in the CCD chamber, causing ice to build up on the front window of the CCD detector, and the Tjautjas station (T) is too far south to cover Eiscat and ARR. The imagers have diagonal fields of view from 70 to $100^{\circ}$. The imager with widest FOV was zenith-mounted at the Skibotn observatory in order to allow projection of start guesses.

\begin{tabular}{|c|c|c|c|c|c|}
\hline Abbr & Station & $\begin{array}{l}\text { Latitude } \\
\left({ }^{\circ} \mathrm{N}\right)\end{array}$ & $\begin{array}{c}\text { Longitude } \\
\left({ }^{\circ} \mathrm{E}\right)\end{array}$ & Imager & $\begin{array}{r}\text { Diagonal FOV } \\
\left(\left(^{\circ}\right)\right.\end{array}$ \\
\hline$A$ & Abisko & 68.36 & 18.82 & 5 & 72 \\
\hline B & Skibotn observatory & 69.35 & 20.36 & 6 & 102 \\
\hline $\mathrm{K}$ & Knutstorp site station, Kiruna & 67.86 & 20.42 & 2 & 72 \\
\hline 0 & IRF optics lab, Kiruna & 67.84 & 20.41 & 1 & 90 \\
\hline$S$ & Silkkimuotka & 68.03 & 21.69 & 4 & 72 \\
\hline $\mathrm{T}$ & Tjautjas & 67.33 & 20.75 & 3 & 72 \\
\hline
\end{tabular}

\section{HotPay 2 event auroral emission ratio retrieval}

C.-F. Enell et al.

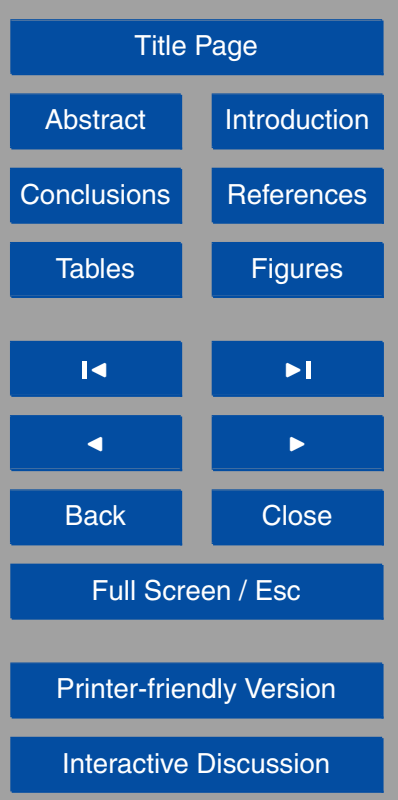




\section{GID}

2, 1-21, 2012

\section{HotPay 2 event auroral emission ratio retrieval \\ C.-F. Enell et al.}

Table 2. ALIS calibration and geometry factors used. Calibration factors are in Rs (Rayleighs per count/s) for the four imagers used in the case study and for $4 \times 4$ pixel on-chip binning.

\begin{tabular}{cllllc}
\hline & \multicolumn{3}{c}{ Calibration factor (Rs) station/imager } & Optical \\
\cline { 2 - 5 } & Skibotn & Abisko & Silkkimuotka & Knutstorp & $\begin{array}{c}\text { depth } \\
\text { exponent }\end{array}$ \\
\hline Emission $(\mathrm{nm})$ & 6 & 5 & 4 & 2 & 0.236 \\
427.8 & 1.36 & 2.38 & 1.94 & 2.30 & 0.116 \\
557.7 & 0.937 & 1.279 & 0.998 & 1.45 & 0.081 \\
\hline
\end{tabular}

Title Page

Abstract

Introduction

Conclusions

References

Tables

Figures



4

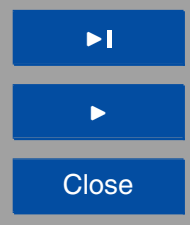

Back

Close

Full Screen / Esc

Printer-friendly Version

Interactive Discussion

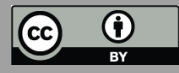




\section{GID}

2, 1-21, 2012

\section{HotPay 2 event auroral emission ratio retrieval \\ C.-F. Enell et al.}

Table 3. Parameters used in the inversion of volume emission rates: maximum altitude of the start guess Chapman profiles and the algorithm(s) used for updating the volume emission rates at backprojection of image ratios.

\begin{tabular}{cccccccc}
\hline & Start profile & \multicolumn{5}{c}{ Tomography } \\
\cline { 3 - 7 } Emission $(\mathrm{nm})$ & peak $(\mathrm{km})$ & Algorithm & Filter & Steps & Algorithm & Filter & Steps \\
\hline 427.8 & 135 & mSIRT & $5 \times 5$ & 2 & mSIRT & $3 \times 3$ & 2 \\
557.7 & 135 & & & \multicolumn{2}{c}{ id. } & & \\
630.0 & 155 & & & \multicolumn{2}{c}{ id. } \\
\hline
\end{tabular}






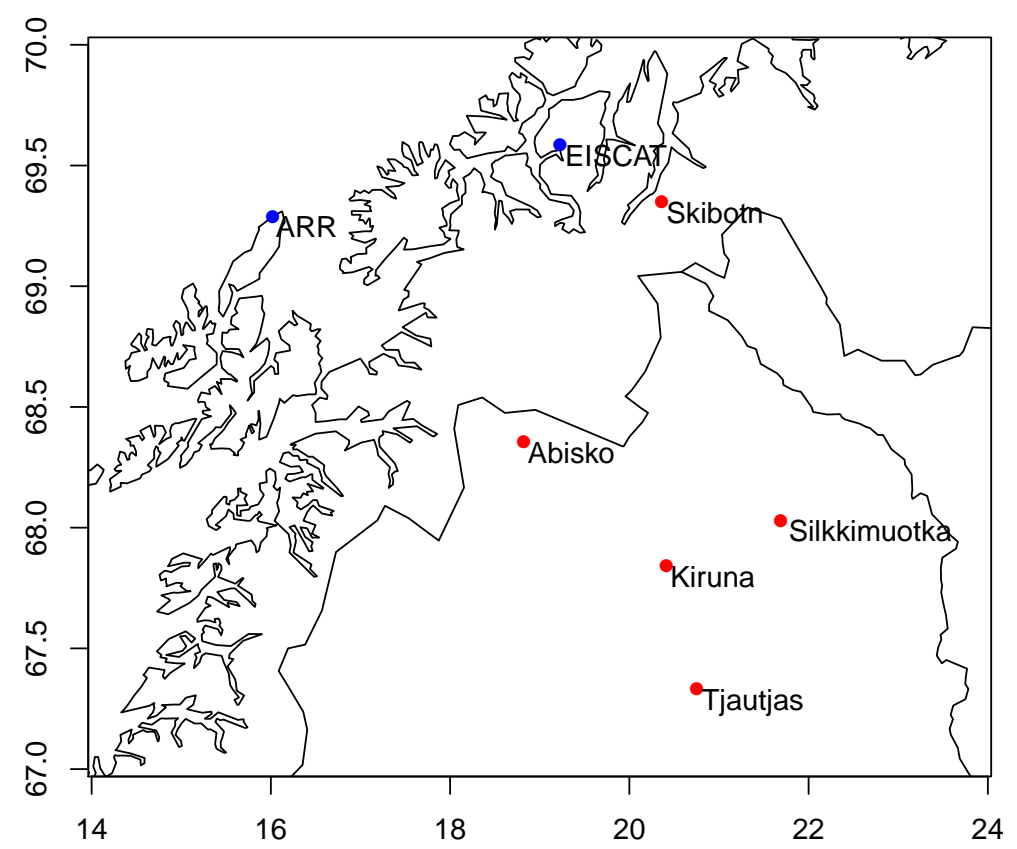

\section{HotPay 2 event auroral emission ratio retrieval}

C.-F. Enell et al.

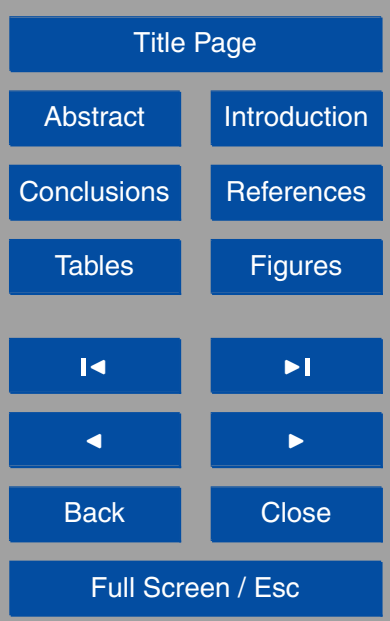

Fig. 1. Map of northern Scandinavia showing the ALIS stations deployed during the winter 2007-2008 (red) and the locations of the EISCAT incoherent scatter radar transmitters and Andøya Rocket Range (ARR; blue).

Printer-friendly Version

Interactive Discussion 




\section{GID}

2, 1-21, 2012

\section{HotPay 2 event auroral emission ratio retrieval \\ C.-F. Enell et al.}

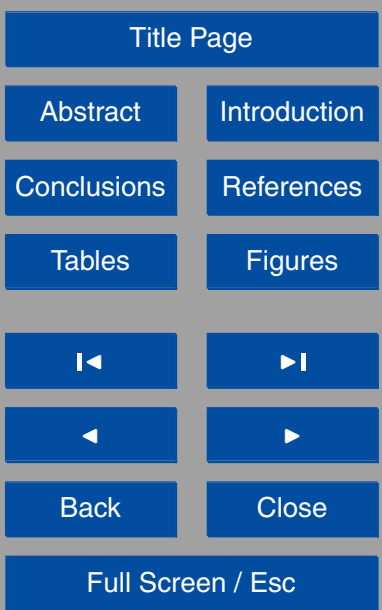

Fig. 2. The overlapping fields of view of the ALIS stations for the camera positions used in this study. The common volume is over the mainland of northern Norway whereas the HotPay 2 measurements (Enell et al., 2011) are from the rocket upleg close to Andøya Rocket Range.

Printer-friendly Version

Interactive Discussion 
4278 volume emission $2008 \quad 1 \quad 31 \quad 18 \quad 4 \quad 30$


6300 volume emission 2008
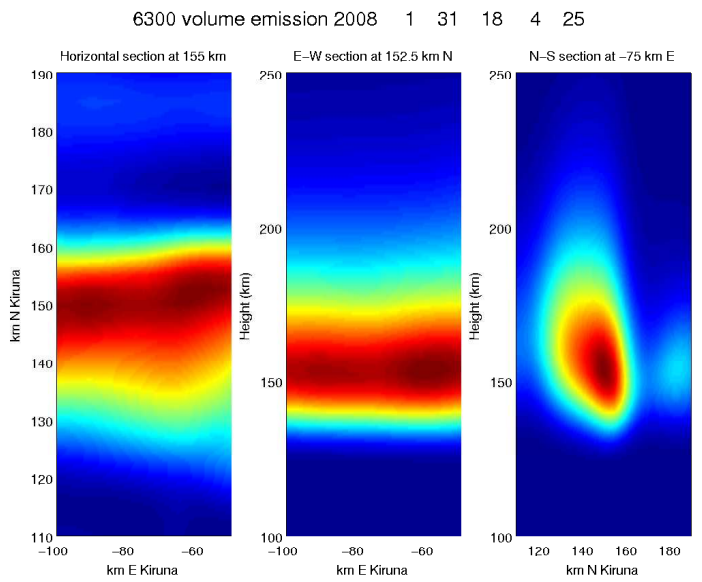

Fig. 3. Interpolated cross sections through the retrieved volume emission rates $\epsilon_{427.8}, \epsilon_{557.7}$ and $\epsilon_{630.0}$ around 18:04:25 UT. Left column: horizontal plane, coordinates east-west and north-south from the Kiruna site. Middle column: vertical cross sections in east-west planes, approximately along the arc. Right columns: vertical cross sections in north-south planes, across the arc. The vertical axis is along the magnetic field.
GID

2, 1-21, 2012

\section{HotPay 2 event auroral emission ratio retrieval}

C.-F. Enell et al.

\begin{tabular}{|c|c|}
\hline \multicolumn{2}{|c|}{ Title Page } \\
\hline Abstract & Introduction \\
\hline Conclusions & References \\
\hline Tables & Figures \\
\hline I4 & \\
\hline 4 & $\bullet$ \\
\hline Back & Close \\
\hline Full Screen / Esc \\
\hline Printer-friendly Version
\end{tabular}

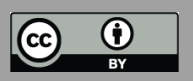






$4278 \quad 18.075$ UT

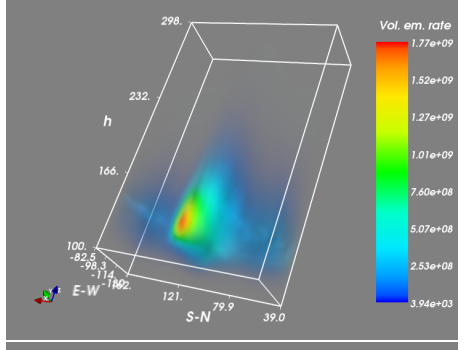

$4278 \quad 18.129$ UT

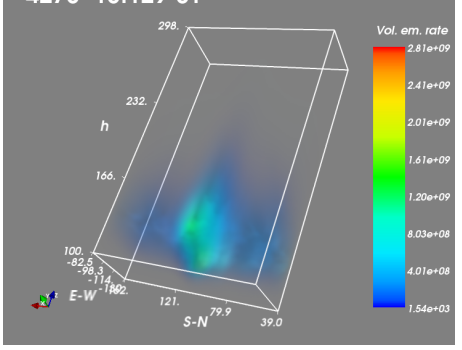

557718.006 UT

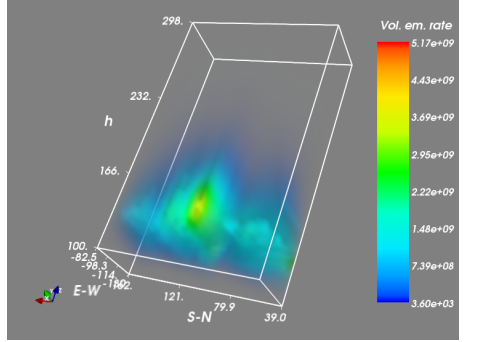

557718.072 UT

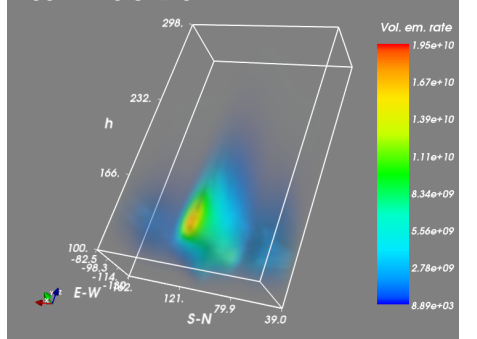

557718.128 UT



630018.007 UT



630018.074 UT



630018.131 UT

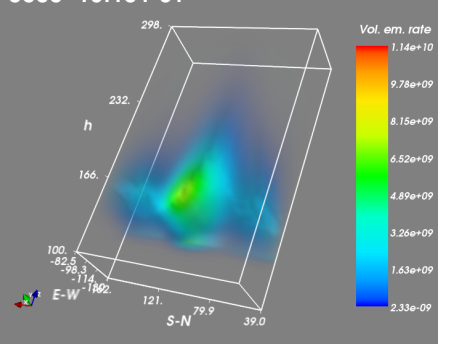

Fig. 4. Volume rendering of volume emission rate estimates $\epsilon_{427.8}, \epsilon_{557.7}$ and $\epsilon_{630.0}$ for arbitrarily selected times.

GID

2, 1-21, 2012

HotPay 2 event auroral emission ratio retrieval

C.-F. Enell et al.



Printer-friendly Version

Interactive Discussion






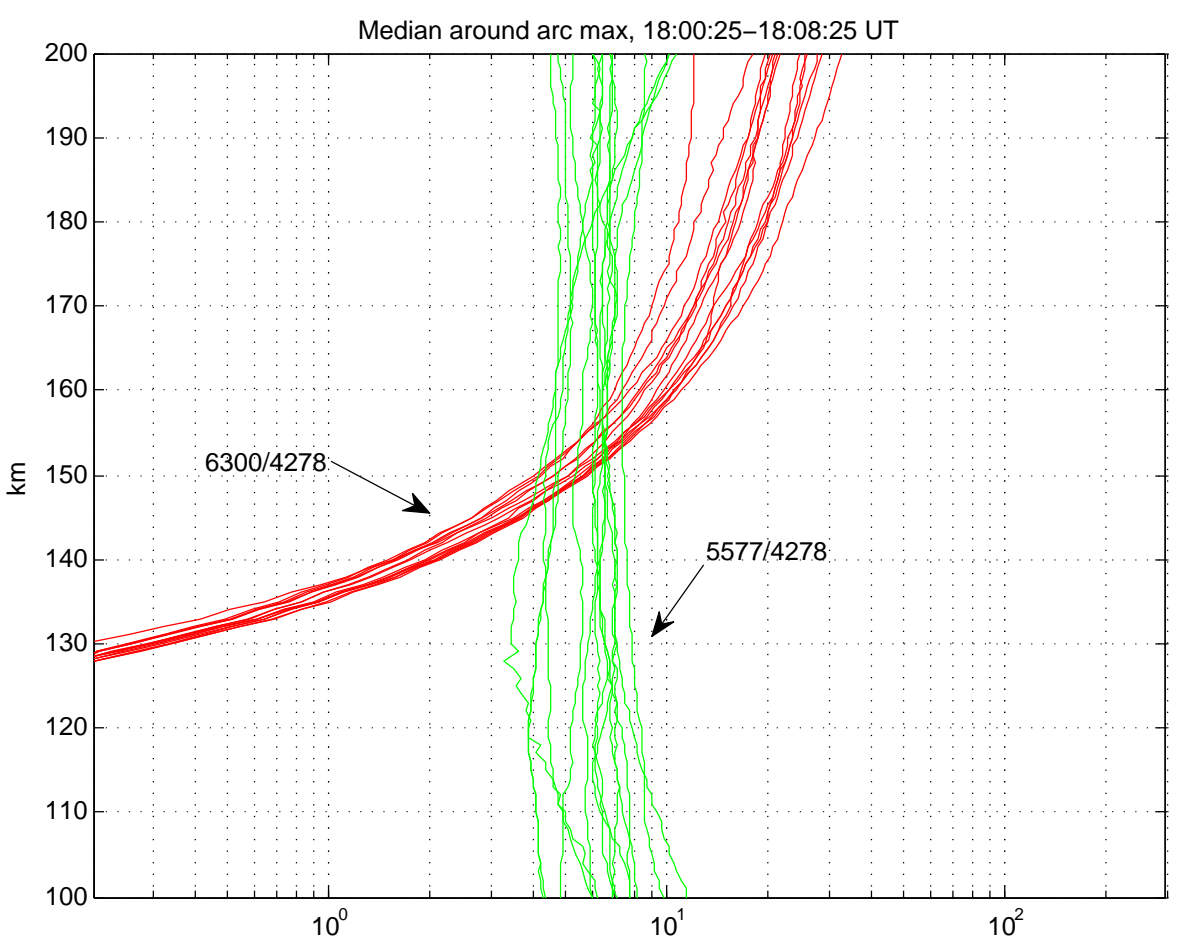

\section{GID}

2, 1-21, 2012

\section{HotPay 2 event auroral emission ratio retrieval \\ C.-F. Enell et al.}

Title Page

Abstract

Introduction

Conclusions

References

Tables

Figures

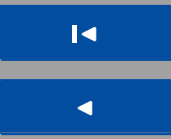

Back

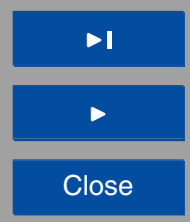

Full Screen / Esc

Fig. 5. Altitude profiles of emission ratios: medians of interpolated altitude profiles in selected maximum regions. The regions were selected manually in the horizontal slices through the blocks of blobs.

Printer-friendly Version

Interactive Discussion






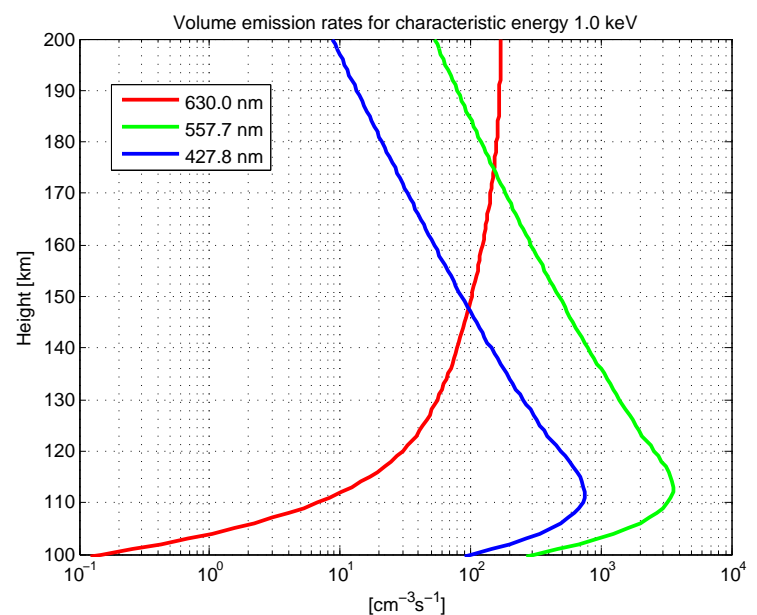

\section{GID}

2, 1-21, 2012

\section{HotPay 2 event auroral emission ratio retrieval}

C.-F. Enell et al.

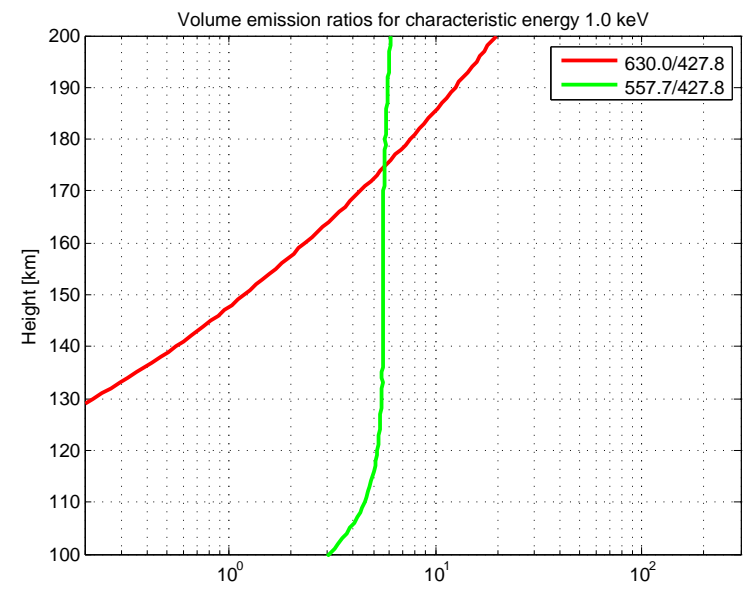

Title Page

Abstract

Introduction

Conclusions

References

Tables

Figures

14

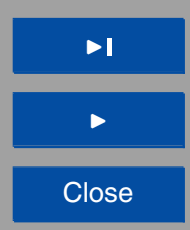

Back

Close

Full Screen / Esc

Printer-friendly Version

Fig. 6. Altitude profiles of emission rates (upper plot) and their ratios (lower plot) calculated for the MSIS background atmosphere of 31 January 2008, 18:00 UT at Tromsø, assuming Maxwellian electron precipitation. Contrary to the absolute emission rates, the ratios do not depend strongly on the characteristic energy and therefore the results for $1.0 \mathrm{keV}$ are shown, although the altitude of maximum emission suggests that the actual precipitation was less energetic.

Interactive Discussion






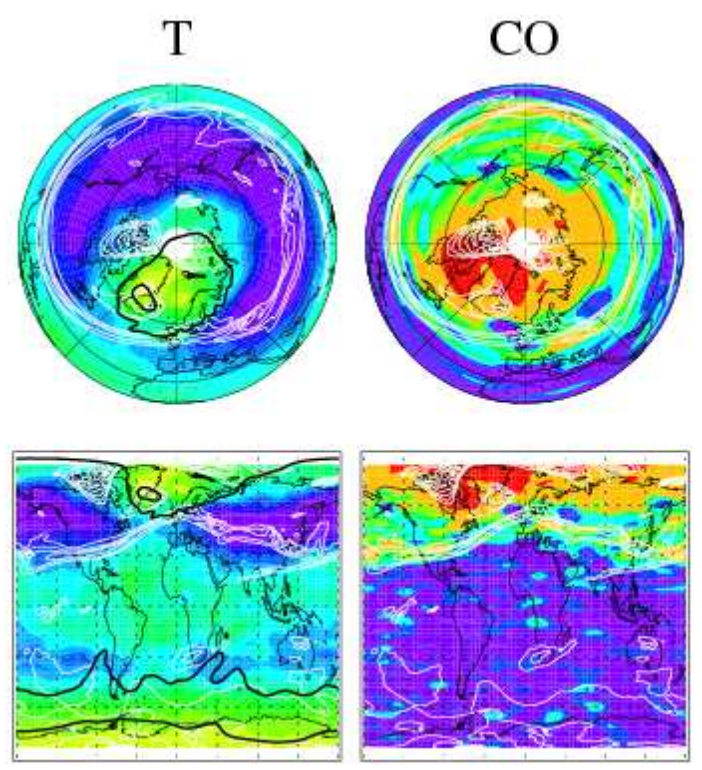

\section{GID}

2, 1-21, 2012

\section{HotPay 2 event auroral emission ratio retrieval \\ C.-F. Enell et al.}

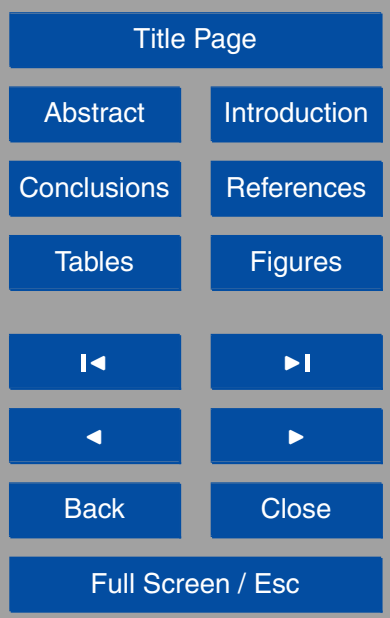

Fig. 7. Maps of temperature and [CO] at the $2700 \mathrm{~K}$ level (approximately $60 \mathrm{~km}$ ) retrieved from EOS Aura MLS measurements. Downwelling of thermospheric air into the mesosphere in a vortex filament NW of Andøya is evident and is consistent with the HotPay 2 NEMI profiles indicating subsidence (Enell et al., 2011). Over the northern Scandinavian mainland however, the profiles are normal.

Printer-friendly Version

Interactive Discussion

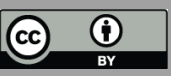

